\title{
Research and Design of Wind and Solar Complementary Electric Sightseeing Boat
}

\author{
Haomin Zhang ${ }^{1 *}$, Xingang $\mathrm{Xu}^{1}$ \\ ${ }^{1}$ School energy and power engineering, Wuhan university of technology, Wuhan, Hubei, 430063, China
}

\begin{abstract}
To solve the problem of rapid development of domestic water tourism and water pollution in scenic waters, windsurfing technology and solar photovoltaic technology are applied to small and mediumsized sightseeing cruise ships. While optimizing the hull design and component coordination, the application of automatic control technology further improves the utilization efficiency of wind and light energy, and achieves the adaptation of the sail angle of attack and the efficient coupling of the two energies. The ship mainly uses the natural resources of solar energy and wind energy. It will not burn fossil fuels during the ship's travel, thus reducing the emission of toxic and harmful substances, which has positive significance for environmental protection. In short, the solar wind-assisted power generation ship studied in this project has remarkable features such as zero emission, high degree of intelligence, significant wind-assisted effect, high efficiency of light energy utilization, and low hull space occupation. Compared with the ordinary lake area cruise ship, the energy-saving and emission reduction effect of the power generation ship is very obvious ${ }^{[1]}$.
\end{abstract}

\section{Introduction}

In recent years, China's tourism industry has developed rapidly, and people have begun to pursue spiritual satisfaction while satisfying the foundation of material life. The golden age of development is ushered in some areas with vast water resources. However, the development of tourism has become more and more serious in the waters of the local lake area. Various types of tourist ships powered by diesel engines and gasoline engines are the main sources of pollution. Its noise, soot and oil leakage and oil leakage have not only caused great damage to the ecological environment of the lake area, but also affected the travel experience of tourists, which is not conducive to the long-term development of the scenic spot. Therefore, it is particularly necessary and urgent to find a sightseeing cruise ship powered by green energy ${ }^{[2]}$.

The wind and solar complementary electric sightseeing boat uses the abundant wind resources generated by the special geographical environment of the lake area as the auxiliary power, and supplies the power to the cruise ship by solar photovoltaic conversion technology, achieving zero emission and zero pollution, effectively reducing the ecological environment of the scenic spot. The destruction. The research further improved the utilization efficiency of wind energy by windsurfing, and realized the intelligentization of windsurfing angle control and the efficient coupling of wind and light energy. In addition, the combination of solar energy and wind energy makes the ship's running performance better and the scope of application is wider. The promotion of the research results can greatly save the operating costs of the cruise ship, and have greater economic and environmental benefits in the long run, in line with the concept of sustainable development. This research will also fill the domestic gap in this area, and it is expected to do deeper research on some cutting-edge technologies.

\section{Proposed study plan}

\subsection{Overall system design}

The photovoltaic power generation-sail propulsion integrated design scheme is arranged, the photovoltaic panel is arranged on the top of the hull, the retractable sail integrated with the flexible photovoltaic panel is arranged on the top, and the wind speed and direction sensor is arranged on the mast. The same side sail is fixed on the same duct, and the sail realizes the retracting action under the rotation of the duct. When the wind can meet the propulsion demand, the sails are erected to drive the vessel to sail; when the wind is insufficient, the sails are deployed to both sides to expand the area of the photovoltaic panels as much as possible. The effect of the preliminary design scheme is shown in Figure 1. 


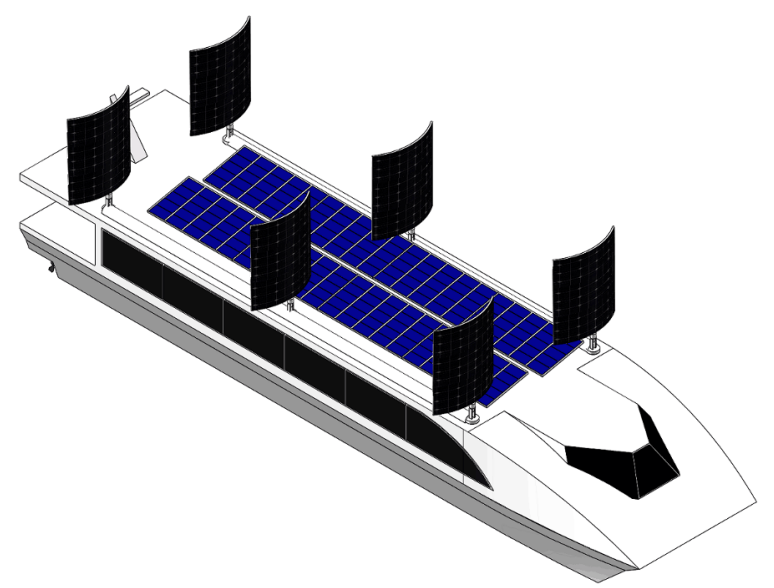

Figure 1. Multi-function ship photovoltaic power generation system renderings

\subsection{Substructure design}

\section{(1) Selection and design of sails}

At present, there are more than ten kinds of sails in the world. The working principle, aerodynamic performance and mechanical structure of various sails are different. Among them, the aerodynamic performance of the exhausted turbine sail is the best, followed by the rectangular sail wing. Because the turbine sail not only needs to provide additional energy to drive the air extractor, it reduces the energy-saving efficiency, and the factors to be controlled are more than the angle of the sail, the angle of the adjustment plate, the opening and closing of the suction hole, and the amount of pumping. In contrast, the rectangular sail wing has a simple control system that consumes less energy and is suitable for assisting ship propulsion.

The main body of the sail design includes the choice of aspect ratio and crown ratio. For the aspect ratio, it is generally necessary to select a sail with a larger aspect ratio, but the larger the aspect ratio, the higher the sail, the higher the wind pressure, the greater the heeling moment and the inclination angle of the ship, and the damage to the ship. Safe sailing. In order to obtain greater thrust, and also to ensure the stability of the ship, does not produce excessive roll angle, the aspect ratio should not be too large, there is a general range given in the literature, it is appropriate to take 1.2-1.6. For the arch ratio, it is advantageous to adopt a large cam ratio, but the arch ratio is too large, which will cause the lateral force to be too large and the invalid thrust to increase, so the arch ratio is generally $0.16-0.18$.

(2) Design of photovoltaic utilization

Solar energy is an inexhaustible source of renewable energy for human beings. It has sufficient cleanliness, absolute safety, relative extensiveness, long life and maintenance-free, resource sufficiency and potential economics. Other advantages have an important position in the long-term energy strategy. The application of solar energy on ships is an inevitable trend of the times. The project will use solar photovoltaic power generation systems to provide energy for ships.

The system utilizes photovoltaic power generation technology to convert solar energy into electrical energy, and then uses DC/DC converters and solar charge and discharge controllers to distribute electrical energy as appropriate. If the sunlight is strong enough, the electric energy is directly supplied to the motor to drive the propeller; if the sunlight is not strong enough, the electric energy is stored in the battery.

(3) Design of wind and light energy conversion device

In order to ensure that the sail can adapt to different angles of wind and sunlight in real time, the project designed a device that can control the sail retracting, so that the sail can adjust the corresponding angle independently for different environmental conditions. The design consists of a support structure, a rack and pinion, a slide rail, a slider and a motor. At the same time, one end of the slide rail is connected to the motor. The gear and the rack fixed by the column slide, thereby changing the angle of the column and changing the angle of the sail. Moreover, one end of the hollow circular tube is also connected to one motor, and by controlling the motor, the hollow tube is rotated, and the column is screwed up or lowered to control the retracting of the sail. The windsurfing effect is shown in Figure 2.

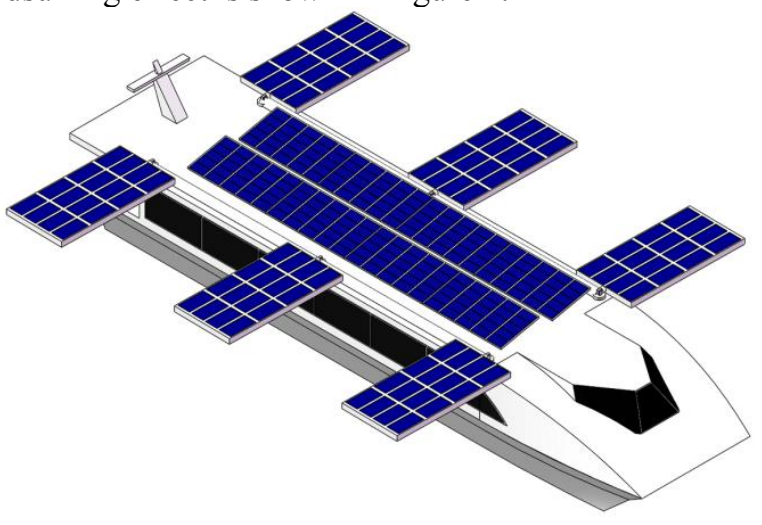

Figure 2. Light energy utilization effect map

\section{Research status at home and abroad}

China's research on wind-assisted navigation started late. In the 1980 s, China gradually developed research on windassisted navigation technology and achieved good results. In 1985, Wuhan Water Transport Engineering College (now Wuhan University of Technology) and Nanjing Shipping Company jointly developed the 2000T arc-shaped sail-sail booster launching test, the energy-saving effect exceeded 50\%; in February 1996, the joint design of 708 and 711, Ningbo The 2500t sail-constructed integrated energy-saving multi-purpose container ship "Mingzhou 22" was launched in Japan. In July 2008, COSCO Group organized the WDS (Wind Wing-Diesel Hybrid Ship) project team to engage in sails. Design study of rudder-paddle control integration. Since then, domestic research on wind-assisted navigation has been almost stagnant. So far, there have been few reports ${ }^{[3]}$.

In September 2003, China's first solar tour vessel was put into use on the water in the Summer Palace. In 2010, China's first independently designed solar and fuel hybrid tour vessel was launched on the Huangpu River. Recently, research institutes and universities such as the China Ship and Ocean Engineering Design and Research Institute have been actively developing or shutting down the development of solar ships and building some solar powered boats. From the perspective of the development of domestic solar ship technology, the 
technology has gradually matured as a research on large-scale ocean-going ships.

\section{Innovative and advanced}

The most important innovation and advancement of this project are mainly reflected in:

1) When the sail is assisted, the self-adaptation of the angle of attack of the sail is utilized;

2) Comparing wind energy with photovoltaic power generation, intelligent selection of the best solution;

3) Photovoltaic power generation is used when there is no wind or wind speed is low. The wind and light conversion device is used to control the windsurfing to both sides of the ship's side to increase the photovoltaic power generation area.

\section{Expected economic benefits and promotional value}

Compared with the traditional propulsion system, the ship intelligent wind and solar hybrid propulsion system has many advantages and economic benefits in ship design, propulsion performance, manufacturing and maintenance. It has high promotion value in many cruise ships and commercial ships. Compared with traditional cruise ships, The project uses windsurfing and photovoltaic technology to provide green energy for the ship's travel. It has a high promotion value in the waters of urban reservoir areas ${ }^{[4]}$.

When the sail is assisted, the windward angle of attack is adaptive, and the maximum beneficial windward area is maintained at any time to achieve the purpose of assisting the cruise ship; and when the light energy utilization effect is good, the photovoltaic power generation area is expanded by the wind and light conversion device. The angular adaptive control system controls the sail to automatically turn to the maximum face-up surface, increasing its power generation efficiency, thereby achieving the purpose of propelling the cruise ship. According to preliminary calculations, taking a traditional diesel-powered cruise ship as an example, a traditional cruise ship carrying 80 people is limited to ten years, consumes about 219 tons of oil, emits 697.80 tons of polluting waste gas, and uses the system to achieve zero emissions and zero pollution. Compared with traditional electric cruise ships, a rough estimate can increase the endurance by $60 \%$ and the maximum speed of $30 \%$.

The energy acquired by the ship intelligent wind-solar complementary propulsion system and the way it is acquired are clean and pollution-free. With the increasing requirements of international laws and regulations on the greening of ships, the effective use of clean ocean energy can reduce the discharge of pollutants from ships. Make full use of natural resources, reduce energy consumption and save costs. It also avoids the risk of polluting urban waters after a ship accident. In addition, this set of wind and solar hybrid propulsion system can be improved to provide auxiliary power and daily electricity for more ship types, such as ocean-going steam carriers and ore carriers ${ }^{[5]}$.

\section{Conclusion}

With the official entry into force of the MARPOL Convention Tier III standard and the implementation of the domestic ship emission control zone, in the context of sustainable development, the emission control standards for marine air pollutants have become more stringent. This paper first analyzes the existing cruise ships, and learns the shortcomings of the current new energy cruise ships. Then, it is determined that the electromechanical-solar panels are designed by using the motor-screw-slide-rack-and-pinion gear structure combined with the solar panels. The composite sail, according to the state and environmental parameters of the ship, adaptively controls the windward angle and the angle of the sail, increases the illuminated area, and realizes the efficient use of both wind and light energy, solving the original system in some cases. Meet the full energy needs of the cruise ship.

\section{References}

1. Yin Kedong, Wei Mengxing, Zhang Tianyu. The reality and thinking of China's maritime power strategy [J]. Marine Development and Management, 2009, 26(6): 3841.

2. PATELS. Utilization and development of marine energy [J]. Shanghai Electric Power, 2009 (1): 32-38

3. Liu Shengguan, Xie Dian, et al. Marine wave, wind and light integrated power ship: China, 201310462964.3[P]. 2013-10-08.

4. Liu Shengguan. Basic platform design and research for offshore wind and wave complementary power generation systems [D]. Beijing: North China Electric Power University, 2014.

5. Lin Shigao Liu Xiaolin. The manipulator attitude smoothing algorithm based on the fifth-order polynomial [J]-Manufacturing Automation 2013(21). 